Rustyani, et al/Jurnal Ekonomi Syariah Teori dan Terapan Vol. 6 No. 2 Februari 2019:270-287; MEASUREMENT OF EFFICIENCY AND PRODUCTIVITY OF AMIL ZAKAT INSTITUTIONS IN INDONESIA BY USING DATA ENVELOPEMENT ANALYSIS METHODS AND MALMQUIST PRODUCTIVITY INDEX

\title{
MEASUREMENT OF EFFICIENCY AND PRODUCTIVITY OF AMIL ZAKAT INSTITUTIONS IN INDONESIA BY USING DATA ENVELOPEMENT ANALYSIS METHODS AND MALMQUIST PRODUCTIVITY INDEX
}

\author{
Selvia Rustyani \\ Departemen Ekonomi Syariah - Fakultas Ekonomi dan Bisnis - Universitas Airlangga \\ Email: Selvia.rustyani@gmail.com \\ Suherman Rosyidi \\ Departemen Ekonomi Syariah - Fakultas Ekonomi dan Bisnis - Universitas Airlangga \\ Email: srosyidi@gmail.com
}

\begin{abstract}
:
This study aims to measure the level of efficiency and productivity of the amil zakat institution in Indonesia. This research is a quantitative research using Data Envelopment Analysis (DEA) and Malmquist Productivity Index (MPI) methods. There are six institutions of amil zakat (LAZ in Indonesia, namely Yayasan Dana Sosial Al-Falah (YDSF), Al-Azhar Peduli Ummat, Aksi Cepat Tanggap (ACT), Yayasan Rumah Yatim Arrohman Indonesia, Pos Kemanusiaan Peduli Ummat (PKPU), and Rumah Zakat Indonesia with 2014 - 2016 annual data as the number of DMUs (decision making units). This study uses an intermediation approach in determining the variables. The input variables of this research are Collected Funds (X1), Total Costs (X2), and Amil Receipts (X3), while the output variables are Disbursed Funds (Y1), and Total Assets (Y2). Two LAZs experienced inefficiencies in 2014 and 2015, namely LAZ YDSF and ACT. Meanwhile, in 2016, all LAZs have achieved optimal levels of efficiency. The results of the MPI analysis showed that in the first year, two LAZs experienced a decline in productivity, namely LAZ Al-Azhar and PKPU. The other four LAZs experienced increased productivity, namely LAZ YDSF, ACT, Rumah Yatim and Rumah Zakat. In the second year, three LAZs experienced increased productivity, namely LAZ AI-Azhar, PKPU and Rumah Zakat. Meanwhile, three other LAZ experienced a decrease in productivity, namely LAZ YDSF, ACT, and Rumah Yatim.
\end{abstract}

Keywords: Efficiency, Productivity, LAZ, DEA, MPI.

I. PENDAHULUAN

Kemiskinan di Indonesia

merupakan masalah yang terus-menerus menjadi agenda nasional dalam berbagai forum, baik pemerintah maupun Lembaga Sosial Masyarakat (LSM). Banyak program, baik dari pemerintah maupun swasta, yang bertujuan mengatasi masalah kemiskinan. Namun itu semua belum secara signifikan dapat mengurangi tingkat kemiskinan di Indonesia. Hal ini sesuai dengan data Badan Pusat Statistik (BPS), yang menyatakan bahwa pada bulan Maret 2017, jumlah penduduk miskin (penduduk dengan pengeluaran per kapita per bulan di bawah Garis Kemiskinan) di Indonesia mencapai 27,77 juta orang atau 10,64\% dari total penduduk. Jumlah tersebut telah mengalami peningkatan sebesar 6,90 ribu orang dibandingkan dengan kondisi September 2016 yang sebesar 27,76 juta orang atau $10,70 \%$ dari total penduduk.

Dalam ekonomi Islam, Al-Qur'an telah menawarkan solusi untuk mengatasi masalah kemiskinan yaitu dengan redistribusi pendapatan yang adil. Di dalam model distribusi tersebut, harta kekayaan tidak boleh hanya berputar pada golongan orang kaya saja, yaitu dalam surat Al-Hasyr ayat 7 sebagai berikut:

1) Jurnal ini merupakan bagian dari skripsi Selvia Rustyani, NIM: 041411431139, yang diuji pada tanggal 11 Oktober 2019. 
Rustyani, et al/Jurnal Ekonomi Syariah Teori dan Terapan Vol. 6 No. 2 Februari 2019:270-287; MEASUREMENT OF EFFICIENCY AND PRODUCTIVITY OF AMIL ZAKAT INSTITUTIONS IN INDONESIA BY USING DATA ENVELOPEMENT ANALYSIS METHODS AND MALMQUIST PRODUCTIVITY INDEX

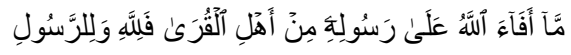

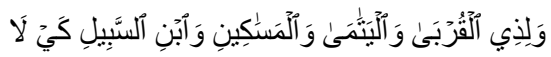

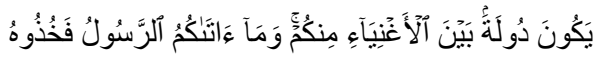

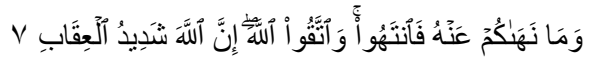

Artinya: "Apa saja harta rampasan (fai') yang diberikan Allah kepada Rasul-Nya (dari harta benda) yang berasal dari penduduk kota-kota maka adalah untuk Allah, untuk Rasul, kaum kerabat, anakanak yatim, orang-orang miskin dan orang-orang yang dalam perjalanan, supaya harta itu jangan beredar di antara orang-orang kaya saja di antara kamu. Apa yang diberikan Rasul kepadamu, maka terimalah. Dan apa yang dilarangnya bagimu, maka tinggalkanlah. Dan bertakwalah kepada Allah. Sesungguhnya Allah amat keras hukumannya.".

Salah satu instrumen redistribusi pendapatan adalah zakat. Zakat merupakan sistem filantropi Islam yang paling utama. Zakat sebagai rukun Islam yang ketiga merupakan bentuk ibadah sekaligus muamalah. Zakat bagi muzaki berfungsi sebagai bentuk ketaatan atau ibadah yang dapat menyadarkan bahwa secara hakikat harta yang dimiliki oleh setiap manusia merupakan milik Allah SWT.

Dari sisi muamalah, zakat berfungsi meringankan beban ekonomi mustahik, serta mempererat persaudaraan (ukhuwah) antara mustahik dan muzaki.Zakat tidak hanya berfungsi menolong perekonomian mustahik, melainkan juga dapat menjadi instrumen penyeimbang antar sektor-sektordi dalam perekonomian nasional. Dalam jangka panjang, tujuan utama zakat adalah mentransformasi para mustahik menjadi muzaki. Semua itu masih harus dibarengi pula dengan sifat ibadah zakat sebagai built-in stabilizer. Hal ini menunjukkan bahwa zakat sangat berpotensi untuk mengatasi senjangan ekonomi dan kemiskinan di suatu negara apabila dikelola dengan baik. Oleh karena tujuan tersebut, keberadaan Organisasi Pengelola Zakat (untuk seterusnya dituliskan OPZ) menjadi sangat penting untuk mengelola dana zakat.

Menurut UU No. 23 tahun 2011 tentang pengelolaan zakat, tujuan pengelolaan zakat di Indonesia adalah meningkatkan efektivitas dan efisiensi pelayanan dalam pengelolaan zakat; dan meningkatkan manfaat zakat untuk mewujudkan kesejahteraan masyarakat dan penanggulangan kemiskinan. Untuk meningkatkan manfaat yang dirasakan oleh masyarakat dalam upaya pengentasan kemiskinan, efisiensi dan produktivitas lembaga zakat menjadi sangat penting dalam menjalankan fungsi intermediasi lembaga zakat. Karena itu, diperlukan suatu pengukuran untuk mengetahui tingkat efisiensi dan produktivitas lembaga zakat. Dengan demikian, hasil pengukuran tersebut dapat menjadi masukan untuk kebijakan LAZ.

\section{LANDASAN TEORI}

Efisiensi merupakan hal yang paling sering digunakan untuk mengukur kinerja suatu perusahaan. Dalam Kamus Besar Bahasa Indonesia (KBBI), pengertian 
Rustyani, et al/Jurnal Ekonomi Syariah Teori dan Terapan Vol. 6 No. 2 Februari 2019:270-287; MEASUREMENT OF EFFICIENCY AND PRODUCTIVITY OF AMIL ZAKAT INSTITUTIONS IN INDONESIA BY USING DATA ENVELOPEMENT ANALYSIS METHODS AND MALMQUIST PRODUCTIVITY INDEX

efisiensi adalah ketepatan cara (usaha, kerja) dalam menjalankan sesuatu (dengan tidak membuang waktu, tenaga, dan biaya.Menurut Srivastava (1999), suatu perusahaan dikatakan efisien apabila perusahaan tersebut dapat meminimalkan biaya dalam menghasilkan output tertentu (input orientated) atau dapat memaksimalkan keuntungannya dengan menggunakan kombinasi input yang ada (output orientated). Efisiensi juga merupakan hal yang paling penting untuk diperhatikan oleh suatu perusahaan agar dapat bertahan dalam persaingan di pasar.

Menurut Farrell (1957) efisiensi perusahaan terdiri dari dua jenis, yaitu:

1. Efisiensi Teknis

Efisiensi ini mencerminkan kemampuan perusahaan untuk memproduksi output semaksimal mungkin dari input yang ada. Efisien secara teknis tidak selalu berarti efisien dalam hal efisiensi harga atau alokatif.

2. Efisiensi Alokatif/Harga

Efisiensi

menggambarkan

perusahaan dalam mengoptimalkan penggunaan inputnya. Unsur yang diperhitungkan dalam input tersebut adalah harga dan teknologi produksinya.

Kedua jenis efisiensi ini kemudian dikombinasikan untuk menghasilkan ukuran efisiensi total atau yang sering disebut dengan efisiensi ekonomis (economic efficiency). Suatu perusahaan dapat dikatakan efisien secara ekonomi jika perusahaan tersebut dapat meminimalkan biaya produksi untuk menghasilkan output tertentu dengan suatu tingkat teknologi yang umumnya digunakan serta pada tingkat harga pasar yang berlaku (Farrel dalam Ascarya dan Yumanita, 2006).

Agama Islam juga sangat menganjurkan efisiensi, baik efisiensi keuangan, waktu, maupun efisiensi berkata yang sia-sia (tidak ada manfaat dan tidak ada keburukan), Islam memerintahkan untuk meninggalkannya. Dalam efisiensi keuangan atau harta, Islam telah melarang (dalam surat AtTakasur) perilaku bermegah-megahan. Dalam efisiensi waktu, Islam memerintahkan (dalam surat Al-Ashr) untuk memanfaatkan waktu yang dimiliki dengan beriman dan beramal sholeh agar tidak masuk ke dalam golongan orang-orang yang merugi. Mengenai efisiensi dalam berkata, Rasulullah shallallahu 'alaihi wa sallam bersabda,

"Barang siapa yang beriman kepada Allah dan Hari Akhir maka hendaklah ia berkata baik atau hendaklah ia diam." (Muttafaq 'alaih: Al-Bukhari, no. 6018; Muslim, no.47)

Menurut Ali dan Ascarya (2010 : 113), tujuan pencapaian efisiensi adalah untuk mencapai keuntungan yang optimal. Dalam Islam, perwujudan keuntungan yang optimal dapat dihasilkan melalui kerja keras atau usaha untuk menghasilkan sesuatu secara optimal dengan tetap menjaga keseimbangan dan etika syariah. Keuntungan yang dihasilkan harus 
Rustyani, et al/Jurnal Ekonomi Syariah Teori dan Terapan Vol. 6 No. 2 Februari 2019:270-287; MEASUREMENT OF EFFICIENCY AND PRODUCTIVITY OF AMIL ZAKAT INSTITUTIONS IN INDONESIA BY USING DATA ENVELOPEMENT ANALYSIS METHODS AND MALMQUIST PRODUCTIVITY INDEX

seimbang dengan kerja keras dan beban yang dikeluarkan, sesuai sabda Rasulullah SAW berikut ini:

"Setiap keuntungan yang didapatkan harus sesuai dengan beban yang dikeluarkan." (HR. Tirmidzi, No. 1285).

Menurut KBBI, produktivitas adalah kemampuan untuk menghasilkan sesuatu. Produktivitas adalah bagaimana menghasilkan atau meningkatkan hasil barang dan jasa setinggi mungkin dengan memanfaatkan sumber daya manusia secara efisien. Oleh karena itu produktivitas sering diartikan sebagai rasio antara keluaran dan masukan dalam satuan tertentu (Sedarmayanti, 2001: 57).

Islam mengajarkan umatnya untuk mengisi hidupnya dengan bekerja dan tidak membiarkan waktunya terbuang siasia. Anjuran bekerja terdapat dalam firman Allah surat At-Taubah ayat 105 yang artinya: "dan katakanlah: "bekerjalah kamu, maka Allah dan RasulNya akan melihat pekerjaanmu itu, dan kamu akan dikembalikan kepada (Allah) Yang Mengetahui akan yang gaib dan yang nyata, lalu diberitakan-Nya kepada kamu apa yang telah kamu kerjakan".

Dalam hadits riwayat Thabrani, Rasulullah SAW bersabda: "Sesungguhnya, di antara perbuatan dosa, ada yang tidak bisa terhapus oleh (pahala) shalat, sedekah, ataupun haji, namun hanya dapat ditebus dengan kesungguhan dalam mencari nafkah penghidupan" (HR. Thabrani). Hadits tersebut menunjukkan betapa tingginya kedudukan bekerja dalam Islam, sehingga terdapat dosa yang hanya bisa dihapuskan dengan bekerja keras.Dalam riwayat lain, tingginya kedudukan bekerja dalam Islam ditunjukkan dalam sebuah cerita bahwa Rasulullah SAW pernah mencium tangan Sa'ad bin Mu'az ketika melihat tangannya kasar setelah bekerja keras mencari kayu. Rasulullah SAW berkata: "Inilah dua telapak tangan yang dicintai Allah".

\section{METODOLOGI PENELITIAN}

Jenis penelitian ini adalah penelitian deskriptif dengan pendekatan kuantitatif. Dalam penelitian ini, yang menjadi objek penelitian adalah Lembaga Amil Zakat di Indonesia. Alasan memilih LAZ sebagai objek penelitian adalah belum banyaknya penelitian yang membahas tentang efisiensi dan produktivitas pada lembaga amil zakat di Indonesia. Populasidalam penelitian ini adalah seluruh lembaga amil zakat (LAZ) di Indonesia. Adapun yang menjadi sampel penelitian adalah enam lembaga amil zakat, yaitu LAZ Yayasan Dana Sosial Al-Falah (YDSF) Surabaya, LAZ Al-Azhar, LAZ Aksi Cepat Tanggap (ACT), LAZ Yayasan Rumah Yatim Ar-rohman Indonesia, LAZ Pos Kemanusiaan Peduli Ummat (PKPU) dan LAZ Rumah Zakat Indonesia.

Pemilihan sampel dari total populasi dilakukan dengan teknik purposive sampling, yakni teknik penentuan sampel dengan pertimbangan tertentu (Sugiyono, 2012:96). Pertimbangan dalam menentukan sampel pada penelitian ini yaitu: 1) Lembaga amil 
Rustyani, et al/Jurnal Ekonomi Syariah Teori dan Terapan Vol. 6 No. 2 Februari 2019:270-287; MEASUREMENT OF EFFICIENCY AND PRODUCTIVITY OF AMIL ZAKAT INSTITUTIONS IN INDONESIA BY USING DATA ENVELOPEMENT ANALYSIS METHODS AND MALMQUIST PRODUCTIVITY INDEX

zakat yang memiliki laporan keuangan periode tahun 2014-2016 terpublikasi di websiteatau bersedia memberikan laporan keuangan LAZ secara langsung. 2) Lembaga amil zakat yang dalam laporan keuangannya memiliki variabelvariabel yang sama, karena metode DEA mensyaratkan hal tersebut.

Ketentuan jumlah decision making unit (untuk selanjutnya dapat ditulis DMU) minimum dalam penelitian ini adalah tiga kali lipat dari jumlah input dan output. Jumlah total input dan output pada penelitian ini adalah lima variabel, maka jumlah DMU minimal yaitu 15 observasi. Jumlah DMU dalam penelitian ini adalah18 berupa enam LAZ dengan tiga tahun periode

Penelitian ini menggunakan pendekatan intermediasi dalam penentuan variabelnya.Tabel di bawah ini merupakan ringkasan variabel input dan output yang digunakan untuk mengukur nilai efisiensi dan produktivitas LAZ dengan pendekatan intermediasi.

Tabel 1.

Variabel Input dan Output

\begin{tabular}{|l|l|}
\hline \multicolumn{1}{|c|}{ Input $(X)$} & \multicolumn{1}{c|}{ Output $(Y)$} \\
\hline Dana Terhimpun $\left(X_{1}\right)$ & Dana Tersalur $\left(Y_{1}\right)$ \\
\hline Total Biaya $\left(X_{2}\right)$ & Aset total $\left(Y_{2}\right)$ \\
\hline Penerimaan Amil $\left(X_{3}\right)$ & \\
& \\
\hline
\end{tabular}

sumber: Ilustrasi Penulis

Jenis data yang digunakan pada penelitian ini adalah data sekunder. Data yang digunakan dalam penelitian ini berupa laporan keuangan periode tahun 2014-2016 semua LAZ yang menjadi objek penelitian. Selain itu, sebagai penunjang, dipakai pula literatur kepustakaan seperti buku-buku, penelitian sebelumnya, jurnal dan sumber lain yang berhubungan dengan materi yang dibahas.

Alat yang digunakan dalam penelitian ini untuk mengukur tingkat efisiensi adalah Banxia Frontier Analyst versi 4.3, sedangkan alat untuk mengukur produktivitas adalah DEAP versi 2.1. Berikut adalah penjelasan mengenai teknik analisis yang digunakan dalam penelitian ini.

Data Envelopment Analysis (DEA) adalah sebuah metode pengukur efisiensi yang menggunakan teknik pemrograman matematis. DEA mengukur efisiensi relatif dari kumpulan decision making unit (DMU) dalam mengelola sumber daya (input) dengan jenis yang sama sehingga menghasilkan output dengan jenis yang sama pula, dimana hubungan bentuk fungsi dari input ke output tidak diketahui (Siswandi:2004).

DEA pada awalnya dikembangkan oleh Farell (1957) yang mengukur efisiensi teknik satu input dan satu output menjadi multi input dan multi output. DEA dipopulerkan oleh Charness, Cooper, dan Rhodes (1978) dengan asumsi Constan Return to Scale (CRS) dan dikembangkan lagi oleh Bunker, Charness, dan Cooper (1994) dengan asumsi Variabel Return to Scale (VRS).Akbar (2009) mengemukakan bahwa DEA memiliki kelebihan sebagai berikut: 
Rustyani, et al/Jurnal Ekonomi Syariah Teori dan Terapan Vol. 6 No. 2 Februari 2019:270-287;

MEASUREMENT OF EFFICIENCY AND PRODUCTIVITY OF AMIL ZAKAT INSTITUTIONS IN INDONESIA BY USING DATA ENVELOPEMENT ANALYSIS METHODS AND MALMQUIST PRODUCTIVITY INDEX

1. DEA dapat mengukur efisiensi berbagai DMU sejenis secara relatif yang mempunyai banyak input dan output.

2. Tidak perlu mencari asumsi bentuk hubungan antar variabel input dan output dari DMU sejenis yang akan diukur efisiensinya.

3. DMU langsung dibandingkan dengan yang sejenis.

4. Faktor input dan output dapat memiliki satuan ukuran yang berbeda. Contohnya input $\left(X_{1}\right)$ dalam satuan orang. Sedangkan output $\left(Y_{1}\right)$ dalam jutaan rupiah. Pengukuran efisiensi tersebut dapat dilakukan tanpa perlu melakukan perubahan satuan dari variabel-variabel yang ada.

Sedangkan kekurangan yang perlu diperhatikan dari metode DEA menurut Akbar, sebagai berikut:

1. Teknik perhitungan yang digunakan dalam DEA adalah extreme point technique, sehingga kesalahan pengukuran berakibat signifikan.

2. DEA hanya mengukur efisiensi relatif dari DMU, yakni menunjukkan perbandingan baik dan buruk dari sebuah DMU dibanding dengan DMU sejenis. DEA tidak mengukur efisiensi absolut.

3. DEA adalah teknik non parametrik, sehingga uji hipotesis secara sistemik tidak mudah dilakukan.

4. Karena tiap DMU menggunakan rumusan linier programming yang terpisah, maka perhitungan secara manual sangat rumit dan lama. Namun hal ini dapat diatasi dengan adanya software.

Malmquist Productivity Index (MPI) pertama kali diperkenalkan oleh menggunakan Caves, Christensen dan Diewert (1982), sebuah pendekatan fungsi jarak untuk menggambarkan teknologi dalam mendefinisikan indeks input, output, dan produktivitas. Estimasi Total Factor Productivity (TFP) dengan pendekatan DEA mengunakan pendekatan index. Ilustrasi TFP indeks seperti berikut: Jika suatu perusahaan dapat menghasilkan output yang sama pada periode $t$ dan $t+1$, namun menggunakan input yg berbeda, yaitu $t+1$ hanya $75 \%$ dari input periode $t$, maka TFP index akan meningkat sebesar 1/0.75 atau 1,3. Contoh ilustrasi lain, jika perusahaan menggunakan input yang sama pada periode $t$ dan $t+1$, namun menghasilkan output yang berbeda yaitu output periode $t+1$ meningkat sebesar $30 \%$ dari output periode $t$, maka TFP index sebesar 1,3 . 
Rustyani, et al/Jurnal Ekonomi Syariah Teori dan Terapan Vol. 6 No. 2 Februari 2019:270-287;

MEASUREMENT OF EFFICIENCY AND PRODUCTIVITY OF AMIL ZAKAT INSTITUTIONS IN INDONESIA BY USING DATA ENVELOPEMENT ANALYSIS METHODS AND MALMQUIST PRODUCTIVITY INDEX

\section{HASIL DAN PEMBAHASAN}

Efisiensi dan produktivitas merupakan konsep yang mengukur rasio output dan input. Dalaminterpretasi hasil, efisiensi memiliki nilai skala 0 (nol) hingga 1 (satu) atau $0 \leq e \leq 1$, dengan e adalah skor efisiensi.Nilai $e=1$ memiliki arti efisien, sedangkan nilai $e<1$ berarti inefisien. Sementara itu, pengukuran produktivitas dengan software DEAP dapat menghasilkan lima nilai sebagai berikut: pertama, EFFCH: perubahan efisiensi (relatif dengan perhitungan CRS), kedua TECHCH: perubahan teknologi, ketiga $\mathrm{PECH}$ : perubahan efisiensi teknis murni (relatif dengan perhitungan VRS), keempat SECH: perubahan efisiensi skala (EFFCH/PECH), dan kelima adalah tabel TFPCH: perubahan faktor produktivitas total dan nilai inilah yang menunjukkan tingkat produktivitas. TFPCH memiliki tiga interpretasi yaitu TFPCH $<1$ yang menunjukan penurunan produktivitas, TFPCH = 1 yang menunjukan tidak ada peningkatan maupun penurunan produktivitas (stagnasi), dan TFPCH $>1$ yang menunjukan peningkatan produktivitas.

Berikut adalah hasil analisis dengan software Banxia Frontier Analyst versi 4.3:
Tabel 2.

Nilai Efisiensi LAZ tahun 2014-2016 (dalam persen)

\begin{tabular}{|l|c|c|c|}
\hline \multicolumn{1}{|c|}{ LAZ } & $\mathbf{2 0 1 4}$ & $\mathbf{2 0 1 5}$ & $\mathbf{2 0 1 6}$ \\
\hline YDSF & 90,3 & 97,5 & 100 \\
\hline Al-Azhar & 100 & 100 & 100 \\
\hline ACT & 85,8 & 98,5 & 100 \\
\hline $\begin{array}{l}\text { Rumah } \\
\text { Yatim }\end{array}$ & 100 & 100 & 100 \\
\hline PKPU & 100 & 100 & 100 \\
\hline $\begin{array}{l}\text { Rumah } \\
\text { Zakat }\end{array}$ & 100 & 100 \\
\hline
\end{tabular}

Sumber: Hasil olah data Banxia Frontier Analyst versi 4.3

Tabel 2. menunjukkan bahwa terdapat dua LAZ yang mengalami inefisien masing-masing pada tahun 2014 dan 2015, yaitu LAZ ACT dan LAZ YDSF. Pada tahun 2014, LAZ ACT memiliki skor efisiensi sebesar 85,8\%. Adapun dalam penelitian Wandayani (2018), ACT mengalami inefisiensi pada tahun 20112013, sedangkan tahun 2014 ACT berhasil mencapai efisiensi optimal. Perbedaan hasil ini dapat terjadi karena perhitungan efisiensi dengan menggunakan DEA merupakan perhitungan efisiensi secara relative. Jika variabel yang digunakan berbeda, maka hasil yang didapatkan juga bisa berbeda. Walaupun variabel yang digunakan berbeda, hasil perhitungan DEA untuk LAZ Al-Azhar, Rumah Yatim, dan Rumah Zakat samasama memiliki hasil efisiensi yang optimal.

Pada tahun 2014, LAZ YDSF memiliki skor efisiensi sebesar 90,3\%. Untuk tahun 2015, nilai efisiensi keduanya mengalami peningkatan, yaitu nilai 
Rustyani, et al/Jurnal Ekonomi Syariah Teori dan Terapan Vol. 6 No. 2 Februari 2019:270-287;

MEASUREMENT OF EFFICIENCY AND PRODUCTIVITY OF AMIL ZAKAT INSTITUTIONS IN INDONESIA BY USING DATA ENVELOPEMENT ANALYSIS METHODS AND MALMQUIST PRODUCTIVITY INDEX

efisiensi LAZ YDSF menjadi $97,5 \%$ dan LAZ ACT menjadi 98,5\%. Hasil penelitian Maulana (2017) menunjukkan bahwa LAZ YDSF 2015 dan 2016 telah mencapai skor efisiensi yang optimal, baik menggunakan asumsi CRS maupun VRS.

Kedua LAZ tersebut terbukti telah berusaha secara maksimal untuk mencapai titik efisien hingga tahun 2016 LAZ YDSF berhasil meningkatkan efisiensinya sebesar 2,5\% untuk mencapai angka 100\%. Adapun LAZ ACT, berhasil meningkatkan efisiensinya sebesar 1,5\% untuk mencapai angka 100\%. Sementara itu, pada tahun 2016 hasil olah data menunjukkan semua LAZ telah mencapai tingkat efisiensi yang optimal yaitu $100 \%$.

Potential improvement merupakan persentase selisih perbandingan antara nilai aktual dengan target pada DMU yang mengalami inefisien. Potential improvement ini bertujuan untuk memperbaiki input dan output yang kurang optimal agar LAZ dapat mencapai titik efisien. Berikut adalah tabel potential improvement pada LAZ yang mengalami inefisiensi. Disebabkan potential improvement pada tahun 2014 dan 2015 memiliki banyak kesamaan, maka akan dijelaskan masing-masing LAZ hanya pada tahun 2014 saja.
Tabel 3.

Potential Improvement LAZ YDSF tahun 2014

\begin{tabular}{|l|r|r|r|}
\hline \multirow{2}{*}{ Variabel } & \multicolumn{3}{|c|}{2014} \\
\cline { 2 - 4 } & \multicolumn{1}{|c|}{ Value } & \multicolumn{1}{c|}{ Target } & $\begin{array}{r}\text { Potential } \\
\text { Improvem } \\
\text { ent (\%) }\end{array}$ \\
\hline Dana Terhimpun & 32.124 .068 .476 & $29.007 .741 .617,05$ & $-9,70$ \\
\hline Total Biaya & 7.719 .056 .503 & $3.436 .303 .403,79$ & $-55,48$ \\
\hline Penerimaan Amil & 7.422 .734 .064 & $4.273 .779 .377,12$ & $-42,42$ \\
\hline Dana Tersalur & 32.616 .207 .093 & $32.616 .207 .093,00$ & 0,00 \\
\hline Aset total & 7.894 .645 .912 & $9.971 .192 .713,14$ & 26,30 \\
\hline
\end{tabular}

Sumber: hasil olah data dengan software Banxia.

Dari sisi input, LAZ YDSF harus mengurangi jumlah dana terhimpun sebesar 9,70\%, dari nilai aktual sebesar Rp 32.124.068.476 menjadi nilai target sebesar Rp. 29.007.741.617,05. Selain itu, LAZ YDSF juga harus mengurangi total biaya dengan jumlah yang cukup besar yaitu $55,48 \%$, dari nilai aktual sebesar Rp. 7.719.056.503 menjadi nilai target sebesar Rp. 3.436.303.403,79. Penerimaan amil juga merupakan input yang harus dikurangi jumlahnya, yaitu sebesar $42,42 \%$, dari nilai aktual sebesar Rp. 7.422.734.064 menjadi nilai target sebesar Rp. 4.273.779.377, 12 .

Dari sisi output, dana tersalur LAZ YDSF telah mencapai nilai yang optimal, sehingga tidak terdapat nilai target yang harus dicapai. Meski demikian, LAZ YDSF harus menambah total asset yang dimiliki yaitu sebesar $26,30 \%$, dari nilai aktual sebesar Rp. 7.894.645.912menjadi nilai target sebesar Rp. 9.971.192.713,14. Selanjutnya, tabel 4.9 di bawah ini menunjukkan potential improvement LAZ ACT tahun 2014. 
Rustyani, et al/Jurnal Ekonomi Syariah Teori dan Terapan Vol. 6 No. 2 Februari 2019:270-287; MEASUREMENT OF EFFICIENCY AND PRODUCTIVITY OF AMIL ZAKAT INSTITUTIONS IN INDONESIA BY USING DATA ENVELOPEMENT ANALYSIS METHODS AND MALMQUIST PRODUCTIVITY INDEX

Tabel 4.

Potential Improvement LAZ ACT tahun 2014

\begin{tabular}{|c|c|c|c|}
\hline \multirow[t]{2}{*}{ Variabel } & \multicolumn{3}{|c|}{2014} \\
\hline & Value & Target & $\begin{array}{l}\text { Potential } \\
\text { Improvem } \\
\text { ent (\%) }\end{array}$ \\
\hline $\begin{array}{l}\text { Dana } \\
\text { Terhimpun }\end{array}$ & $\begin{array}{r}91.150 .521 . \\
473\end{array}$ & $78.180 .217 .495,67$ & $-14,23$ \\
\hline Total Biaya & $\begin{array}{r}16.529 .100 \\
346\end{array}$ & $10.983 .204 .003,42$ & $-33,55$ \\
\hline $\begin{array}{l}\text { Penerimaan } \\
\text { Amil }\end{array}$ & $\begin{array}{r}8.270 .584 \\
703\end{array}$ & $11.220 .337 .122,29$ & $-38,59$ \\
\hline $\begin{array}{l}\text { Dana } \\
\text { Tersalur }\end{array}$ & $\begin{array}{r}77.969 .369 \\
051\end{array}$ & $77.969 .369 .051,00$ & 0,00 \\
\hline Aset total & $\begin{array}{r}23.046 .392 . \\
995\end{array}$ & $23.046 .392 .995,00$ & 0,00 \\
\hline
\end{tabular}

Sumber: hasil olah data dengan software Banxia.

Dari sisi input, LAZ ACT harus mengurangi jumlah dana terhimpun sebesar 14,23\%, dari nilai aktual sebesar Rp. 91.150.521.473menjadi nilai target sebesar Rp. 78.180.217.495,67. Selain itu, LAZ ACT juga harus mengurangi total biaya yaitu sebesar 33,55\%, dari nilai aktual sebesar Rp. 16.529.100.346 menjadi nilai target sebesar Rp. 10.983.204.003,42. Penerimaan amil juga merupakan input yang harus dikurangi jumlahnya, yaitu sebesar 38,59\%, dari nilai aktual sebesar Rp. 18.270.584.703 menjadi nilai target sebesar Rp. 11.220.337.122,29. Adapun dari sisi output, dana tersalur dan aset total LAZ ACT telah mencapai nilai yang optimal, sehingga tidak terdapat nilai target yang harus dicapai.

Berdasarkan nilai potential improvement, agar dapat mencapai nilai efisiensi 100\%, LAZ YDSF harus mengurangi jumlah dana terhimpun, total biaya, dan penerimaan amil, serta menambah aset total. Sementara itu, LAZ ACT juga harus mengurangi jumlah dana terhimpun, total biaya, dan penerimaan amil, tanpa harus mengubah jumlah pada variabel output, karena aset total dan dana tersalur telah mencapai nilai optimal. Pengurangan jumlah dana terhimpun dilakukan untuk menghindari dana ZIS yang terhimpun tersebut menjadi tertimbun terlalu banyak dalam waktu yang lama. Idealnya, lembaga zakat di Indonesia saling berlomba-lomba dalam menghimpun dana. Sebagai lembaga yang memiliki fungsi utama intermediaris, selain menghimpun dana, tantangan bagi lembaga zakat adalah menyalurkan dana secara tepat, efektif dan efisien. Faktanya, setiap lembaga zakat memiliki kapasitas kerjanya masing-masing dalam mengelola dana ZIS, baik dari sumber daya manusia, maupun manajemen serta ruang lingkupnya. Oleh karena itu, terlalu banyaknya dana ZIS yang dihimpun juga memiliki potensi tertimbunnya dana tersebut, jika tidak diimbangi dengan penyaluran yang efektif, efisien dan tepat sasaran. Dengan demikian, semakin banyak dana ZIS yang terhimpun tidak selalu berarti bahwa lembaga zakat tersebut memiliki kinerja yang paling baik, namun juga perlu diperhatikan mengenai kapasitas lembaga zakat tersebut dalam mengelola dana ZIS. Dalam agama Islam, hal itu juga diajarkan kepada umat Islam untuk menjadi umat pertengahan, seperti yang termaktub dalam Al-Qur'an surat AlBaqarah ayat 143 yang artinya: "Dan yang demikian itu Kami telah menjadikan kalian (umat Islam) sebagai umat 
Rustyani, et al/Jurnal Ekonomi Syariah Teori dan Terapan Vol. 6 No. 2 Februari 2019:270-287;

MEASUREMENT OF EFFICIENCY AND PRODUCTIVITY OF AMIL ZAKAT INSTITUTIONS IN INDONESIA BY USING DATA ENVELOPEMENT ANALYSIS METHODS AND MALMQUIST PRODUCTIVITY INDEX

pertengahan agar kalian menjadi saksi atas (perbuatan) manusia dan agar Rasul (Muhammad) menjadi saksi atas perbuatan kalian" (QS Al Baqarah: 143).

Selaras dengan hasil penelitian Rahmayanti (2014), yang menyatakan bahwa penerimaan dana ZIS (dana terhimpun) Rumah Zakat tahun 2009-2011 harus dikurangi karena melebihi target yang harus dicapai. Namun, tidak ada penjelasan terkait analisis pengurangan dana terhimpun tersebut. Jika melihat perbandingan jumlah dana terhimpun dan dana tersalur, pada tahun 2014-2015 LAZ YDSF memiliki dana tersalur yang lebih besar dibanding dana terhimpunnya. Keputusan untuk melakukan penyaluran lebih besar pada tahun itu biasanya terjadi karena lembaga zakat memiliki dana tertimbun dari tahun-tahun sebelumnya yang dapat digunakan untuk menutupi kelebihan penyaluran. Manajemen YDSF sendiri memiliki aturan untuk menyisakan saldo danazakat maksimal Rp. 200 juta setiap tahunnya. Di sisi lain, dana tersalur yang lebih besar dibanding dana terhimpun juga dapat terjadi karena lembaga zakat sebagai lembaga filantropi.

Selain mengurangi dana terhimpun, LAZ YDSF dan ACT juga harus mengurang total biaya. Diketahui pada tahun 2014, terjadi gempa bumi di China dan pada tahun 2015 terjadi gempa bumi di Nepal. ACT sebagai LAZ dengan skala global, turut memberikan bantuan ke berbagai negara-negara yang mengalami bencana. Tidak mengherankan, untuk dapat menyalurkan bantuan tersebut, ACT perlu mengeluarkan biaya yang tidak sedikit.

Pada penelitian-penelitian sebelumnya, banyak hasil yang menunjukkan bahwa lembaga zakat harus mengurangi biaya. Namun, variabel yang digunakan bukan total biaya melainkan komponen biaya, seperti biaya operasional, biaya tenaga kerja, dan biaya sosialisasi. Misalnya saja pada penelitian Wandayati (2018), LAZ ACT pada tahun 2011 - 2013 harus mengurangi biaya operasional dan biaya gaji karyawan. Penelitian lain, yaitu Aini (2012), LAZ YDSF pada tahun 2008 harus mengurangi biaya operasional sebesar $69,29 \%$ dan biaya gaji karyawan sebesar $73,07 \%$. Adapun untuk variabel total biaya belum ditemukan penelitian sebelumnya. Pemilihan total biaya sebagai variabel dalam penelitian ini karena terdapat ketidaksamaan komponen biaya pada laporan kevangan masing-masing LAZ. Padahal, metode DEA mensyaratkan variabel yang digunakan harus sama. Walaupun belum ada penelitian yang menggunakan total biaya sebagai variabel, hal ini tidak menjadi masalah, hanya saja memiliki kekurangan yaitu tidak dapat mendeskripsikan pada komponen mana biaya harus dikurangi.

Kebanyakan penelitian menggunakan variabel biaya operasional dan biaya gaji karyawan, dan rata-rata hasil penelitian mengharuskan biayabiaya tersebut untuk dikurangi. Sebenarnya, dalam menjalankan 
Rustyani, et al/Jurnal Ekonomi Syariah Teori dan Terapan Vol. 6 No. 2 Februari 2019:270-287; MEASUREMENT OF EFFICIENCY AND PRODUCTIVITY OF AMIL ZAKAT INSTITUTIONS IN INDONESIA BY USING DATA ENVELOPEMENT ANALYSIS METHODS AND MALMQUIST PRODUCTIVITY INDEX

operasionalnya, LAZ tidak mungkin tanpa mengeluarkan biaya. Biaya gaji karyawan misalnya, jika LAZ memiliki orientasi untuk mengeluarkan sesedikit mungkin biaya, maka akan berpotensi untuk menggaji karyawan tidak sesuai dengan yang seharusnya menjadi hak amil. Sehingga, dapat disimpulkan bahwa bukan perkara meminimalisasikan biaya, namun mengefisienkan biaya agar biaya yang dikeluarkan sesuai dengan kebutuhan dan tidak boros.

Selanjutnya, YDSF dan ACT juga harus mengurangi jumlah penerimaan amil. Pengurangan jumlah penerimaan amil ini merupakan penyelarasan atas target dana terhimpun yang juga harus dikurangi. Penerimaan amil merupakan bagian amil atas dana ZIS yang berhak diambil. Oleh karena itu, jumlah penerimaan amil pasti bergantung pada besarnya jumlah dana ZIS yang terhimpun. Jika dalam potential improvement, dana terhimpun harus berkurang maka penerimaan amil juga akan berkurang. Di dalam Peraturan BAZNAS nomor 1 tahun 2016 BAB IV pasal 8 ayat 1 disebutkan bahwa besaran hak amil ditentukan paling banyak sebesar $1 / 8$ atau $12,5 \%$ dari dana zakat. Pada ayat 2, dijelaskan bahwa jika penerimaan amil dari dana zakat pada ayat 1 tidak mencukupi, biaya operasional dapat menggunakan alokasi dari dana infak/sedekah dan dana sosial keagamaan lain paling banyak sebesar $20 \%$. Ditemukan dalam laporan keuangan ACT, besaran bagian amil atas dana zakat melebihi ketentuan yang berlaku, yaitu sebesar 12,90\% pada tahun 2014 dan $12,65 \%$ pada tahun 2015. Adapun YDSF telah sesuai dengan ketentuan yang berlaku. Penelitian sebelumnya yang menggunakan variabel penerimaan amil ini tidak banyak ditemukan. Pada penelitian Difanda (2017), menggunakan variabel sejenis yaitu dengan sebutan distribusi amil. Variabel ini bukan sebagai variabel input, melainkan sebagai variabel output. Hasil penelitian Difanda (2017), menyatakan bahwa BAZNAS provinsi Jawa Timur tahun 2013 harus meningkatkan distribusi amil sebesar 13,91\%, BAZNAS provinsi DKI tahun 2016 harus meningkatkan distribusi amil sebesar $17,07 \%$.

Temuan menarik selanjutnya, potential improvement pada LAZ YDSF menunjukkan bahwa perlu dilakukan peningkatan pada aset total. Jika dilihat berdasarkan laporan keuangan, hal ini dapat terjadi karena aset yang dimiliki YDSF adalah yang paling kecil dibanding dengan LAZ lainnya. Selain itu, jumlah aset kelolaan YDSF juga masih terbilang sedikit, yaitu hanya berupa piutang bergilir dengan jumlah saldo akhir pada tahun 2014 sebesar Rp. 397.062.500, sedangkan pada tahun 2015 sebesar Rp. 459.696.500.

Berkaitan dengan pendapat yang menyatakan bahwa setiap LAZ memiliki kapasitasnya masing-masing dalam mengelola dana ZIS, untuk dapat meningkatkan kapasitas tersebut, dapat dilakukan berbagai macam upaya. Misalnya seperti, meningkatkan kualitas dan kuantitas sumber daya manusia 
Rustyani, et al/Jurnal Ekonomi Syariah Teori dan Terapan Vol. 6 No. 2 Februari 2019:270-287; MEASUREMENT OF EFFICIENCY AND PRODUCTIVITY OF AMIL ZAKAT INSTITUTIONS IN INDONESIA BY USING DATA ENVELOPEMENT ANALYSIS METHODS AND MALMQUIST PRODUCTIVITY INDEX

(SDM), meningkatkan teknologi, dan membuka kantor cabang untuk memperluas ruang lingkup aktivitas. Selain untuk meningkatkan kapasitas, pengadaan teknologi dan pembukaan kantorcabang baru juga dapat dilakukan untuk meningkatkan aset total LAZ. Pada penelitian-penelitian sebelumnya belum ada yang menggunakan variabel total asset, melainkan menggunakan variabel asset tetap dan asset lancar. Hal ini sama saja, hanya dalam penggunaan variabel total asset tidak dapat mendeskripsikan dari komponen mana sumber inefisiensi tersebut berasal. Berbeda dengan hasil penelitian ini, hasil penelitian Aini (2012) menunjukkan bahwa LAZ YDSF tahun 2008 harus mengurangi asset lancar sebesar $5,14 \%$, dan asset tetap sebesar $48,04 \%$. Pengurangan asset ini disebabkan oleh penggunaan asset yang kurang efektif dan produktif, misalnya penambahan kantor cabang dengan lokasi yang kurang strategis serta tanpa diimbangi dengan sosialisasi kepada masyarakat.

Tabel di bawah ini merupakan hasil pengolahan data terhadap variabel pada laporan keuangan LAZ tahun 20142016 menggunakan Malmquist Productivity Index (MPI) dengan output orientated dan asumsi VRS. Penggunaan asumsi CRS ataupun VRS sebenarnya tidak memiliki pengaruh terhadap malmquist DEA, karena keduanya sama-sama digunakan untuk menghitung berbagai jarak yang digunakan untuk membangun indeks malmquist. Namun, dalam software DEAP tetap harus mengisi option asumsi tersebut. Dipilihnya asumsi VRS, karena untuk menyamakan dengan asumsi yang digunakan dalam pengukuran efisiensi. Berikut hasil pengolahan data yang menunjukkan tingkat produktivitas LAZ.

Tabel 5.

Hasil pengolahan data pada Malmquist Productivity Index (MPI)

\begin{tabular}{|l|l|l|l|l|l|}
\hline \multirow{2}{*}{ LAZ } & \multicolumn{5}{|c|}{ 2014-2015 } \\
\cline { 2 - 6 } & effch & Techch & pech & sech & Tfpch \\
\hline YDSF & 1,118 & 0,928 & 1,061 & 1,054 & 1,038 \\
\hline Al-Azhar & 1,000 & 0,897 & 1,000 & 1,000 & 0,897 \\
\hline ACT & 1,317 & 0,928 & 1,136 & 1,159 & 1,222 \\
\hline $\begin{array}{l}\text { Rumah } \\
\text { Yatim }\end{array}$ & 1,000 & 1,039 & 1,000 & 1,000 & 1,039 \\
\hline PKPU & 1,027 & 0,964 & 1,000 & 1,027 & 0,991 \\
\hline $\begin{array}{l}\text { Rumah } \\
\text { Zakat }\end{array}$ & 1,221 & 0,953 & 1,000 & 1,221 & 1,164 \\
\hline Mean & 1,108 & 0,950 & 1,032 & 1,074 & 1,053 \\
\hline
\end{tabular}

\begin{tabular}{|l|l|l|l|l|l|}
\hline \multicolumn{1}{|c|}{ LAZ } & \multicolumn{5}{c|}{$2015-2016$} \\
\hline & effch & techch & pech & sech & ffpch \\
\hline YDSF & 0,859 & 1,058 & 1,025 & 0,837 & 0,908 \\
\hline Al-Azhar & 1,000 & 1,107 & 1,000 & 1,000 & 1,107 \\
\hline ACT & 1,017 & 0,875 & 1,015 & 1,002 & 0,889 \\
\hline Rumah Yatim & 1,000 & 0,812 & 1,000 & 1,000 & 0,812 \\
\hline PKPU & 1,000 & 1,219 & 1,000 & 1,000 & 1,219 \\
\hline Rumah Zakat & 1,019 & 1,121 & 1,000 & 1,019 & 1,141 \\
\hline Mean & 0,981 & 1,021 & 1,007 & 0,974 & 1,002 \\
\hline
\end{tabular}

Sumber: Laporan Keuangan LAZ tahun 2014-2016 diolah dengan DEAP 2.1

Dari tiga periode yang diteliti, terdapat dua hasil pengolahan data. Hal tersebut dikarenakan perhitungan produktivitas merupakan nilai perubahan atas total factor productivity. Perubahan tersebut melibatkan sekurang-kurangnya dua production technology sets. Mengingat bahwa total faktor produktivitas adalah hasil dari perkalian antara perubahan efisiensi teknis (EFFCH) dan perubahan teknologi (TECHCH), maka peningkatan dan penurunan 
Rustyani, et al/Jurnal Ekonomi Syariah Teori dan Terapan Vol. 6 No. 2 Februari 2019:270-287; MEASUREMENT OF EFFICIENCY AND PRODUCTIVITY OF AMIL ZAKAT INSTITUTIONS IN INDONESIA BY USING DATA ENVELOPEMENT ANALYSIS METHODS AND MALMQUIST PRODUCTIVITY INDEX

produktivitas dapat dipastikan dengan membandingkan nilai-nilai EFFCH dan TECHCH. Hal ini dapat dirumuskan sebagai berikut:

Dengan kata lain, peningkatan produktivitas dapat dijelaskan menjadi hasil dari peningkatan atau penurunan efisiensi, peningkatan atau penurunan teknologi atau keduanya. Demikian pula, perubahan efisiensi keseluruhan (overall efficiency) dalam hal ini ditunjukkan pada nilai EFFCH adalah hasil perkalian dari efisiensi teknis murni (pure efficiency change/PECH) dengan perubahan efisiensi skala (scale efficiency change/SECH). Dengan kata lain, nilai efisiensi skala sangat ditentukan oleh nilainilai EFFCH dan PECH yang juga dapat dirumuskan sebagai berikut:

Berdasarkan olah data di atas, dapat diketahui bahwa pada tahun pertama terdapat dua LAZ yang memiliki nilai TFPCH kurang dari satu, yaitu LAZ AlAzhar dan PKPU. Sementara itu, empat LAZ lainnya memiliki nilai TFPCH lebih dari satu, yaitu LAZ YDSF, ACT, Rumah Yatim, dan Rumah Zakat. Sebagai contoh interpretasi hasil olah data di atas, LAZ PKPU memiliki nilai TFPCH sebesar 0,991, yang artinya terjadi penurunan produktivitas pada LAZ tersebut sebesar $0,9 \%$. Hal itu disebabkan oleh penurunan technical change (TECHCH) atau tingkat teknologi yang digunakan sebesar 3,6\%, namun tidak dapat dicover dari peningkatan nilai efficiency change (EFFCH) yang hanya sebesar 2,7\%. Peningkatan EFFCH tersebut berada di bawah rata-rata yang sebesar 10,8\%. Hal ini dapat terjadi karena LAZ PKPU ingin meningkatkan tingkat efisiensinya, sehingga PKPU melakukan penghematan dengan mengurangi biaya yang dikeluarkan untuk teknologi. Pengurangan biaya teknologi inilah yang menjadi penyebab penurunan produktivitas LAZ PKPU. Di sisi lain, Rumah Yatim mengalami peningkatan produktivitas sebesar $3,9 \%$. Peningkatan ini terdiri dari peningkatan penggunaan teknologi sebesar 3,9\% dengan tingkat efisiensi yang tidak terjadi perubahan. Peningkatan produktivitas LAZ Rumah Yatim hanya disebabkan oleh peningkatan teknologi yang digunakan, misalnya terdapat layanan donasi online, serta menjalin kerjasama dengan mitra seperti bukalapak.com dan kitabisa.com.

Adapun pada tahun kedua, terdapat tiga LAZ yang memiliki nilai TFPCH kurang dari satu, yaitu LAZ YDSF, ACT dan Rumah Yatim. Tiga LAZ lainnya memiliki nilai lebih dari satu, yaitu LAZ AIAzhar, PKPU, dan Rumah Zakat. LAZ Rumah Zakat memiliki nilai TFPCH sebesar 1,141, yang berarti LAZ tersebut mengalami peningkatan produktivitas sebesar $14,1 \%$. Nilai ini dipengaruhi oleh peningkatan efficiency change sebesar $1,9 \%$ sekaligus juga peningkatan teknologi sebesar $12,1 \%$. Hal ini dapat terjadi karena LAZ Rumah Zakat melakukan peningkatan teknologi yang digunakan yaitu dengan adanya layanan donasi online, host to host mandiri, host to host ATM Bersama, Infaq Card (I-Card), membuat platform sharinghappiness.org, 
Rustyani, et al/Jurnal Ekonomi Syariah Teori dan Terapan Vol. 6 No. 2 Februari 2019:270-287; MEASUREMENT OF EFFICIENCY AND PRODUCTIVITY OF AMIL ZAKAT INSTITUTIONS IN INDONESIA BY USING DATA ENVELOPEMENT ANALYSIS METHODS AND MALMQUIST PRODUCTIVITY INDEX

bekerjasama dengan payment channel yaitu satuloket.com, blibli.com, bukalapak.com, tokopedia, paypro, dan paypal, serta adanya program shopping charity. Peningkatan teknologi ini juga merupakan upaya untuk meningkatkan efisiensi, misalnya dengan adanya teknologi ini dapat berkurang pula biaya operasional, biaya sewa gerai di mall, dan upah petugas gerai serta memberi kemudahan kepada donator untuk membayar zakat, infak, dan sedekah.

Di sisi lain, terjadi penurunan produktivitas pada LAZ YDSF sebesar 9,2\%. Penurunan ini terjadi karena adanya penurunan efficiency change sebesar $14,1 \%$, walaupun tingkat teknologi yang digunakan mengalami peningkatan sebesar 5,8\%. Hal ini dapat terjadi karena LAZ YDSF berupaya untuk meningkatkan tingkat teknologi yang digunakan, misalnya dengan adanya aplikasi android YDSF Mobile, dan situs jual beli online KUMYDSF (Komunitas Usaha Mandiri YDSF). Namun, penggunaannya masih kurang optimal, sehingga menyebabkan penurunan efisiensi karena biaya pengadaan teknologi. Potensi YDSF sangatlah besar, namun perlu adanya kerjasama dengan mitra lain, misalnya, perusahaan yang bergerak di bidang teknologi digital serta sinergi dengan berbagai lembaga atau institusi agar potensi tersebut dapat dioptimalkan.

Pada tahun pertama, semua LAZ mengalami penurunan teknologi dengan rata-rata penurunan sebesar $6,6 \%$ kecuali Rumah Yatim yang mengalami peningkatan teknologi sebesar 3,9\%. Sementara itu, di tahun kedua, hanya LAZ YDSF yang mengalami penurunan efficiency change yaitu sebesar 14,1\%. Untuk LAZ Rumah Zakat, baik pada tahun pertama maupun kedua, tidak terjadi perubahan pada nilai efisiensi teknis murni sehingga perubahan overall efficiency semata-mata hanya merupakan eskalasi dari efisiensi skala yaitu sebesar 22,1\% pada tahun pertama, dan $1,9 \%$ pada tahun kedua.

Penelitian sebelumnya tentang perhitungan produktivitas lembaga zakat dengan menggunakan MPI belum banyak ditemukan. Terdapat satu penelitian di Indonesia yaitu penelitian Al-Parisi (2017), yang bertujuan selain mengukur efisiensi dan produktivitas, juga menentukan faktor-faktor yang mempengaruhi tingkat efisiensi dengan menggunakan regresi tobit. Hasil penelitian menunjukkan bahwa terdapat empat OPZ yaitu YBM BRI, Rumah Zakat, PKPU, dan BAZNAS mengalami peningkatan produktivitas. Hal ini ditandai dengan skor TFPCH lebih dari 1 (satu). Adapun satu OPZ, yaitu Dompet Dhuafa mengalami penurunan produktivitas dengan skor 0,845.

Selain itu, penelitian Norazlina dan Abdul Rahim (2013), bertujuan mengukur efisiensi dan produktivitas lembaga zakat di Malaysia serta mengidentifikasikan faktor-faktor yang mempengaruhi tingkat efisiensi dengan menggunakan regresi tobit. Hasil penelitian menyatakan bahwa TFPCH lembaga zakat di Malaysia telah meningkat pada tingkat rata-rata $2,4 \%$ 
Rustyani, et al/Jurnal Ekonomi Syariah Teori dan Terapan Vol. 6 No. 2 Februari 2019:270-287; MEASUREMENT OF EFFICIENCY AND PRODUCTIVITY OF AMIL ZAKAT INSTITUTIONS IN INDONESIA BY USING DATA ENVELOPEMENT ANALYSIS METHODS AND MALMQUIST PRODUCTIVITY INDEX

selama 2003-2007. Peningkatan ini dikaitkan dengan TECHCH 3,5\% dan EFFCH $-0,1 \%$. Sayang sekali, penelitian ini memiliki perbedaan objek yang diteliti sehingga tidak dapat dibandingkan dengan penelitian Norazlina dan Abdul Rahim.

$$
\text { Efisiensi dan produktivitas }
$$

merupakan dua kinerja yang dapat berjalan searah dan juga dapat berlawanan. Berjalan searah karena efisiensi juga merupakan bagian dari komponen produktivitas. Adapun yang berjalan berlawanan bagi lembaga yang tidak mampu mengoptimalkan sumber daya yang ada, baik teknologi maupun SDM LAZ. Pengadaan teknologi dapat memunculkan biaya, jika teknologi tidak dimanfaatkan secara optimal, maka biaya yang dikeluarkan akan tidak sebanding dengan hasil yang diperoleh. Adapun pilihan untuk tidak menggunakan teknologi juga harus sejalan dengan peningkatan kualitas dan kuantitas SDM. Peningkatan kualitas SDM ini juga tidak terlepas dari biaya, misalnya biaya pelatihan. Di era digitalisasi ini, sangatlah wajar jika LAZ ikut menggunakan teknologi yang ada guna mengoptimalkan penghimpuan dan penyaluran zakat serta pembuatan database LAZ tersebut. Namun, hal tersebut juga perlu diimbangi dengan peningkatan kualitas SDM. Bukan SDM sekadar bertujuan menghimpun dan menyalurkan dana ZIS sebanyakbanyaknya, tetapi SDM yang peduli dengan permasalahan ummat, dan memiliki tujuan dakwah untuk mengedukasi masyarakat tentang pentingnya zakat, infak dan sedekah.

\section{Simpulan}

Terdapat dua LAZ yang mengalami inefisiensi masing-masing pada tahun 2014 dan 2015, yaitu LAZ YDSF dan ACT. Sementara itu, pada tahun 2016 hasil olah data menunjukkan semua LAZ telah mencapai tingkat efisiensi yang optimal. Adapun hasil analisis MPI menunjukkan bahwa pada tahun pertama terdapat dua LAZ yang memiliki nilai TFPCH kurang dari satu, yaitu LAZ AlAzhar dan PKPU. Sementara itu, empat LAZ lainnya memiliki nilai TFPCH lebih dari satu, yaitu LAZ YDSF, ACT, Rumah Yatim, dan Rumah Zakat. Pada tahun kedua, terdapat tiga LAZ yang mengalami peningkatan produktivitas, yaitu LAZ AlAzhar, PKPU, dan Rumah Zakat. Sementara itu, tiga LAZ lainnya mengalami penurunan produktivitas yaitu LAZ YDSF, ACT, dan Rumah Yatim.

\section{DAFTAR PUSTAKA}

Al-Qur'an dan Terjemah.

Al-Hadits.

Abd Wahab, Norazlina dan Abdul Rahman Abdul Rahim. 2013. Determinants of Efficiency of Zakat Institutions in Malaysia: A Nonparametric Approach, Asian Journal of Business and Accounting 6 (2), hlm. $33-64$.

Aini, Novi Nurul. 2012. Efisiensi Lembaga Zakat Nasional Menggunakan Metode Data Envelopment Analysis Periode 2008-2009. Skripsi. Surabaya: Universitas Airlangga. 
Rustyani, et al/Jurnal Ekonomi Syariah Teori dan Terapan Vol. 6 No. 2 Februari 2019:270-287; MEASUREMENT OF EFFICIENCY AND PRODUCTIVITY OF AMIL ZAKAT INSTITUTIONS IN INDONESIA BY USING DATA ENVELOPEMENT ANALYSIS METHODS AND MALMQUIST PRODUCTIVITY INDEX

Akbar, Nasher. 2009. Analisis Efisiensi Organisasi Pengelola Zakat Nasional dengan Pendekatan Data Envelopment Analysis. Jurnal TAZKIA Islamic Finance and Business Review, Vol. 4 No. 2, 760 784.

Aksi Cepat Tanggap https://act.id/

Al-Azhar Peduli Ummat https://alazharpeduli.com/

Al-Parisi, Salman. 2017. Analisis Determinan Lembaga Zakat di Indonesia dan Tingkat Produktivitas-nya. Bogor: Smart Consulting.

Ali, Mahbubi, dan Ascarya. 2010. Analisis Efisiensi Baitul Maal Wat Tamwil Dengan Pendekatan Two Stage Data Envelopment Analysis (Studi Kasus Kantor Cabang BMT MMU dan BMT UGT Sidogiri). Jurnal TAZKIA Islamic Finance and Business Review, Vol. 5 No. 2, $110-$ 125.

Badan Amil Zakat Nasional https://pusat.baznas.go.id/

Badan Pusat Statistik. https://www.bps.go.id/

Banker, R.D., Charnes, A., and Cooper, W.W. 1984. "Some Models for Estimating Technical and Scale Inefficiency in Data Envelopment Analysis", Management Science, 30 (9), 1078-92.

Beik, Irfan Syauqi, dkk. 2012. Economic Estimation and Determinations of Zakat Potential in Indonesia.

Caves et al. 1982. "The Economic Theory of Index Number and The
Measurement of Input, Output, and Productivity". Econometrica, 50(6):1393-1414.

Charnes, A., W.W. Cooper, and E. Rhodes. 1978. "Measuring the Efficiency of Decision Making Units", European Journal of Operation Research, 2, 6, 429-44.

Coelli, T.J, D.S.P. Rao, and G.E. Battese. 1998. Introduction to Efficiency and Productivity Analysis. Boston: Kluwer Academic Publisher.

Coelli, T .J, 1996. A Guide to DEAP Version 2.1: A Data Envelopment Analysis (Computer) Program. Armidale: CEPA The University of New England.

Difanda, Renaldy Dafi. 2017. Analisis Efisiensi BAZNAS Provinsi dengan Metode Data Envelopment Analysis (DEA). Skripsi. Surabaya: Universitas Airlangga.

Farrell, M.L. 1957. "The Measurement of Productive Efficiency", Journal of The Royal Statistical Society, 120, p.253-281.

Kamus Besar Bahasa Indonesia (KBBI) daring, (http://kbbi.web.id/pusat, diakses 19 Juli 2018).

Krishnasamy, Geeta, dkk. 2003. Malaysian Post Merger Bank's Productivity: Application of Malmquist Productivity Index. Petaling Jaya: Monash University Malaysia.

Maulana, Ahmad. 2017. Efisiensi Kinerja Lembaga Zakat Nasional (Studi Kasus: YDSF, Yatim Mandiri, \& 
Rustyani, et al/Jurnal Ekonomi Syariah Teori dan Terapan Vol. 6 No. 2 Februari 2019:270-287;

MEASUREMENT OF EFFICIENCY AND PRODUCTIVITY OF AMIL ZAKAT INSTITUTIONS IN INDONESIA BY USING DATA ENVELOPEMENT ANALYSIS METHODS AND MALMQUIST PRODUCTIVITY INDEX

Lazisnu). Skripsi. Surabaya:

Universitas Airlangga.

Mubarok, Abdulloh, dan Baihaqi Fanani.

2014. Penghimpunan Dana Zakat Nasional (Potensi, Realisasi, dan Peran Penting Organisasi Pengelola Zakat). Jurnal PERMANA, Vol. V, No.2, hlm. 14.

Munir, Misbahul dan A. Djalaluddin. 2006.

Ekonomi Qur'ani: Doktrin Reformasi Ekonomi dalam Al-Qur'an. Malang: UIN Malang Press.

Pos Kemanusiaan Peduli Ummat https://pkpu.org/

PUKAS BAZNAS. 2016. Outlook Zakat Indonesia 2017. Jakarta: BAZNAS.

Qardhawi, Yusuf. 2007. Hukum Zakat, (terj. Salman Harun, dkk.), Bogor: Pustaka Litera Antarnusa.

Rahmayanti, Annisa. 2014. Efisiensi Lembaga Amil Zakat Dalam Mengelola Dana Zakat di Indonesia (Studi Kasus: PKPU, Rumah Zakat, dan BAMUIS BNII). Skripsi. Jakarta: UIN Syarif Hidayatullah.

Republik Indonesia. Undang-undang Nomor 23 Tahun 2011 tentang Pengelolaan Zakat. 2011. Jakarta: kemenag.go.id. Undang-undang Nomor 38 Tahun 1999 tentang Pengelolaan Zakat. 1999. Jakarta: dpr.go.id. . Peraturan Pemerintah Nomor 14 Tahun 2014. 2014. Jakarta: pid.baznas.go.id.

. Pedoman Transliterasi Arab-Latin. Surat Keputusan Bersama Menteri
Agama RI dan Menteri Pendidikan dan Kebudayaan RI Nomor 158/1987 dan0543 b/U/1987, tanggal 22 Januari 1988.

Rosyidi, Suherman. 2006. Pengantar Teori Ekonomi. Edisi Revisi. Jakarta: PT Raja Grafindo Persada.

Rumah Zakat Indonesia https://rumahzakat.org/

Rusdyana, Aam. 2017. Pelatihan DEA dan Indeks Malmquist, Surabaya: Universitas Airlangga.

Sedarmayanti. 2001. Sumber Daya Manusia dan Produktivitas Kerja. Bandung: Mandar Maju.

Sugiyono.2012. Metode Penelitian Kuantitatif, Kualitatif, dan $R$ \& $D$. Bandung: Alfabeta.

Surjaningsih, Ndari, dan Bayu Panji Permono. 2014. "Dinamika Total Factor Productivity Industri Besar dan Sedang Indonesia". Buletin Ekonomi Moneter dan Perbankan, hlm. 277 - 308. Jakarta: Bank Indonesia.

Wandayati, Nur Ika. 2018. Analisis Efisiensi Lembaga Amil Zakat Nasional di Indonesia dengan Metode Data Envelopment Analysis Tahun 20102016. Skripsi. Surabaya: Universitas Airlangga.

Wahyuny, Ikka Nur. 2015. Analisis Efisiensi Organisasi Pengelola Zakat Nasional dengan Metode Data Envelopment Analysis (Studi di Badan Amil Zakat Nasional, Dompet Dhuafa, dan Lazis Nahdlatul Ulama Periode 
Rustyani, et al/Jurnal Ekonomi Syariah Teori dan Terapan Vol. 6 No. 2 Februari 2019:270-287; MEASUREMENT OF EFFICIENCY AND PRODUCTIVITY OF AMIL ZAKAT INSTITUTIONS IN INDONESIA BY USING DATA ENVELOPEMENT ANALYSIS METHODS AND MALMQUIST PRODUCTIVITY INDEX

2013.Skripsi. Yogyakarta: Universitas Negeri Yogyakarta.

Yayasan Dana Sosial Al-Falah https://ydsf.org/
Yayasan Rumah Yatim Ar-rohman Indonesia https://rumah-yatim.org/ 2000-2015. Frontier Analyst Manual version 4.3. Banxia Holdings Ltd. (https://banxia.com/downloads/) 